\title{
A Clinico Microbiological Profile of Diabetic Foot Patients
}

\author{
Honeypalsinh H. Maharaul ${ }^{1}$, Foram Mehta ${ }^{2}$, Ketul Shah ${ }^{3}$, Aiam Perumal Asokan ${ }^{4}$ \\ ${ }^{1}$ Associate Professor, Department of Surgery, Smt. B. K. Shah Medical Institute \& Research Centre, Sumandeep \\ Vidyapeeth Deemed to be University (An Institution), Pipariya, Vadodara, ${ }^{2}$ Resident, Department of Surgery, \\ Smt. B. K. Shah Medical Institute \& Research Centre, Sumandeep Vidyapeeth Deemed to be University (An \\ Institution), Pipariya, Vadodara, ${ }^{3}$ Assistant Professor, Department of Surgery, Smt. B. K. Shah Medical Institute \& \\ Research Centre, Sumandeep Vidyapeeth Deemed to be University (An Institution), Pipariya, Vadodara, ${ }^{4}$ Resident, \\ Department of Surgery, Smt. B. K. Shah Medical Institute \& Research Centre, Sumandeep Vidyapeeth Deemed to \\ be University (An Institution), Pipariya, Vadodara
}

\begin{abstract}
Introduction: Diabetic foot syndrome (DFS), a complex disorder, affects diabetics. It is the unique anatomy of the foot that leads to potentially serious infection. Three cardinal aetiological factors that predispose to diabetic foot ulcers are ischaemia, neuropathy and infection. DFUs are challenging to cure as often the diagnosis is delayed; there is presence of ischaemia, infection with multidrug-resistant organism and extension of infection to the bones. This study was conducted with the aim to determine the clinical and microbiological profile of diabetic foot patients and to assess their outcome.
\end{abstract}

Methodology: Sixty five male and female patients of 18 and above age that presented with diabetic foot ulcers were enrolled over a period of 18 months.

Results: Of the 65 patients enrolled, $70.77 \%(n=46)$ were males while $29.23 \%(n=19)$ were females. Male to female ratio was 2.4:1. Diabetic foot ulcers are common in elderly population. Most commonly seen in the age group of 51 to 60 years. When we evaluated the Wagner grade of the ulcers, it was observed that majority of the patients had Wagner grade III ulcer (44.62\%) followed by grade II ulcer in $24.62 \%$ of the patients. None of the patients enrolled in the present study had wagner grade I ulcer. When the risk factors presence was evaluated in the patients, $63.08 \%$ patient had suffered trauma, this was followed by peripheral neuropathy which was present in $60.00 \%$ patients. Among the patient enrolled, $36.92 \%$ were smokers. $63.08 \%$ patients had diabetes for more than 10years while 20\% had diabetes of 5-10 years duration and only $16.92 \%$ patients had diabetes of less than 5 years. We observed that USG showed presence peripheral vascular disease in $41.54 \%$ patients, which is considerably high. In the present study X-ray showed presence of Charcot's joint, osteomyelitis, fracture and osteoporosis in $10.77 \%, 24.62 \%, 3.08 \%$ and $4.62 \%$ patients respectively. We observed that in our study, anemia was present in large proportion of patients, $67.69 \%$, in the present study. In the present study, ulcer was managed conservatively in $38.46 \%$ of the patients. I \& D was performed in $35.38 \%$ of the patients. While amputation was performed in $12.31 \%$ of the patients. In the present study, the following organisms were isolated: Staphylococcus aureus, Pseudomonas Aeruginosa, Klebsiella pneumonia, Streptococcus pyogenes and Proteus Mirabilis were present in $36.92 \%$, 9.23\%, $13.85 \%, 18.46 \%$ and $10.77 \%$ patients, respectively. Thus the most common isolate was Staphylococcus

\section{Corresponding Author:}

\section{Dr. Ketul Shah}

Assistant Professor, Department of Surgery, Smt. B.K. Shah Medical Institute \& Research Centre, Sumandeep Vidyapeeth Deemed to be University (An Institution), Pipariya, Vadodara

e-mail: shahketul2009@yahoo.com

Phone: 9724507634 aureus followed by Klebsiella pneumonia. We observed that $50 \%$ staphylococcus aureus isolates were resistant to methicillin, that is methicillin resistant staphylococcus aureus. However, the isolated staphylococcus did not demonstrate resistance to vancomycin or linezolid. Gram negative organisms showed no resistance to Piperacillin+tazobactum, 
Imipenem and Meropenem in the present study. Amputation was performed in all the patients with Wagner grade IV and V ulcers, while it occurred in $48.15 \%$ patients with vasculopathy and $33.33 \%$ patients with neuropathy. It was also observed that in those patients with proteus infection, amputation had to be performed in $100 \%$ patients.

Conclusion: Diabetic foot ulcers pose a significant burden on the patients and on the health care system. The cost of disability, loss of work and lower extremity amputation extends beyond the economic impact, with regards to patient quality of life.

Proper management of diabetic infections requires appropriate antibiotic selection based on culture and antimicrobial susceptibility results; however, initial management comprises empirical antimicrobial therapy, which is often based on susceptibility data extrapolated from studies performed on general clinical isolates.

Keywords: Diabetic foot, diabetes, microorganisms.

\section{Introduction}

Diabetes: Amongone of the oldest known diseasesis diabetes. ${ }^{[1]}$

Diabetesmellitusametabolicdisorderthatischaracterised by impairedcarbohydratemetabolismafflictslargenumber of peopleofallsocialconditionsthroughouttheworldandiscauseoflargemanynumber of complications; thusposingsignificantthreattohealthresourcesglobally. It results incomplications, suchasdiabeticnephropathy, neuropathyandretinopathy. ${ }^{[2,3]}$ Diabetesareuniquegroupinthewaythattheyaremorepronetodevelopinfectionsthanothers.

Epidemiology: Around 422 millionpatientsofdiabetesexitsglobally. ${ }^{[4]}$ By 2030 this number may dou- ble. ${ }^{[2]}$ Asper International Diabetes Federation, 7.1\% of the adults are affectedwithdiabetes. ${ }^{[5]}$ In the USA, around $8.3 \%$ populationisdiabetic. ${ }^{[2]}$ ItisalsoacommonprobleminIndia where $8.7 \%$ diabeticpopulationexists. ${ }^{[6]}$ Asoftoday, Aug 2019, around 72.94 millionpeopleinIndiahavediabetesand this will worsen with time. ${ }^{[7]}$ Theproblemisdiabeticsareata 10 foldhigherchanceofhospitalizationduevariousinfections. ${ }^{[8]}$

Diabetic footulcer: Within creased prevalence of diabetes globally, there is increaseinits complications too. ${ }^{[9]}$ Diabetic foot syndrome (DFS), a complex disorder, affects diabetics. ${ }^{[10,11]}$ The common estulcersiteisdorsalorplantar regions followed by heel and plantar metatarsals. ${ }^{[12]}$ Ulcers classification is as in the table 1 below:

Table 1. Wagner's Classification of Diabeticfootulcers (Wagner, 1987). ${ }^{[13]}$

\begin{tabular}{|c|l|}
\hline \multicolumn{2}{|c|}{ Grade Description } \\
\hline 0 & Whenthereisnoulcereveninahigh-riskfoot \\
\hline 1 & Thesearesuperficialulcerthatinvolvethefullthicknessoftheskinbutdoesnotextendtounderlyingtissues \\
\hline 2 & $\begin{array}{l}\text { Thesearedeepulcerulcersthatextendtillligamentsandmusclehowevertheboneisnotinvolvedandalsothereisnoformationofab- } \\
\text { scess }\end{array}$ \\
\hline 3 & Thesearedeepulcerthatareassociatedwithcellulitisorabscessformationandareoftenassociatedwithosteomyelitis \\
\hline 4 & Inthisthereislocalgangrene \\
\hline 5 & Thewholefootisgangrenous \\
\hline
\end{tabular}

It is the unique anatomy of the foot that leads to potentially serious infection. Diabetic foot ulcers (DFUs) arise due to its two major complications:

(i) Neuropathy (ii) Vasculopathy (microaswellasmacro)

Neuropathy makes the foot insensate to chronic or acute injuries. Diabetic suffer from repeated traumas that go non-recognized. This results in development of causes callosities, cracks, fissures, and ulcerformation. 
The diabetic foot ulcers are complex from other ulcersin away because micro-vascularcirculationisimpairedduetoatherosclerosisthatlimitsthebloodcausingischemiaanddecreaseaccessofphagocyticcellsandantibioticstoinfectedarea. $^{[14]}$

DFUs are infection prone as high blood sugar levels provide ideal media for the organisms growth. As the immune system is compromised in diabetics there is rapid and relentless growth of organism resulting in local sepsis and sometimes lifethreatening septicemia. The infection causes further ischemia by microthrombi formation that result in necrosis and gangrene. Sometimes the infection is so severe that it calls for limb amputation. ${ }^{[15]}$

DFUs are chronic in nature, requiring repeated hospitalization. The patient is sometimes exposed to several antibiotics thereby increasing risk of multidrugresistant infection development.

Epidemiology of DFU: India has 3.6\% prevalence of diabetic foot ulcers. ${ }^{[6]}$ Between $12 \%-25 \%$ of diabetics are at its risk. ${ }^{[16-18]}$ Around $40 \%-80 \%$ DFUs are associated with morbidity and mortality.

Problem Statement: DFUs have become a source of morbidity and are a leading cause of hospitalization in diabetics to the extent that $20 \%$ of hospital admissions in diabetics are due to DFU. These can also lead to infection, gangrene, amputation and sometimes even death in the absence of necessary care. ${ }^{[2]}$

Chronic DFU is one that fails to heal within 30 days and is a precipitator of amputation. ${ }^{[19]}$ Amputation of even one limb significantly increases the cardiac risk of the patients. Thus, it is utmost necessary to save limb, not only from the view point of mobility and morbidity but also the view point of cardiac safety.

To decrease the burden of DFUs and increase the awareness among the masses, a novel project 'Step- byStep Improving diabetes Foot care in the developing world' has been initiated in India, it also trains people on treatment of trivial foot lesions. ${ }^{[20]}$

Three cardinal aetiological factors that predispose to diabetic foot ulcers are ischaemia, neuropathy and infection. DFUs are challenging to cure as often the diagnosis is delayed; there is presence of ischaemia, infection with multidrug-resistant organism and extension of infection to the bones. Fetid foot is combined infection involving bone and soft tissue. ${ }^{[21]}$

Proper management of diabetic foot infection is a difficult and debatable. It is necessary to isolate and identify the causative microbial flora and initiate appropriate antibiotic therapy. A multidisciplinary approach is required to manage the DFU and its infections. $^{[21]}$

The infections are usually caused by polymicobials thus requiring proper management with appropriate antibiotic selection. ${ }^{[15]}$ Identification of the causative organism is must for the optimal management. Certain factors like microbes in lower limb, metabolic factors, earlier use of antibiotics and hygiene of feet play an important role in this. ${ }^{[12]}$ Under some specific conditions even fungal infection of diabetic foot can occur.

Infection by multi-drug resistant organisms (MDROs) is common in diabetics and this makes them recalcitrant to healing. ${ }^{[22]}$

Pathogens such as methicillin resistant $S$ aureus (MRSA) or vancomycin-resistant Enterococci, are commonly isolated and are usuall resistant to most antimicrobial agents. ${ }^{[2]}$ Presence os MDRO infection is influenced by previous use of antibiotic and the duration for which they were administered, hospitalization frequency and duration, presence of osteomyelitis and proliferative retinopathy. ${ }^{[2]}$

Predominantly the aerobes that are commonly seen in patients with infected DFUs are Staphylococcus aureus, coagulasenegative staphylococci, Streptococcus species, Enterococcus species, Corynebacterium species, Enterobacteriaceae and Pseudomonas aeruginosa. However, many infections are polymicrobial and sometimes even fungi may be present. ${ }^{[2]}$ Fungi are common in chronic foot ulcers in elderly diabetics having high Wagener grade and poor glycemic control.

This study was conducted with the aim to determine the clinical and microbiological profile of diabetic foot patients and to assess their outcome.

\section{Materials and Method}

This prospective, interventional study was carried out in the General Surgery Department of Dhiraj Hospital, for one year and half year from April 2018 to September 2019. Those patients that had diabetic foot ulcers were enrolled in the study which was conducted as per Ethical guidelines and local regulatory guidelines. 


\section{Inclusion Criteria:}

1. Patients of both the sexes that had an age of 18 years or older.

2. All patients who reported to surgery department with diabetic foot ulcers.

3. Patient who gave written informed consent.

\section{Exclusion Criteria:}

1. Patients who did not agree to give consent for participation in the study.

\section{Results and Discussion}

In the present study 65 patients that had diabetic foot ulcer and had presented to the general surgery department were enrolled.

1. Gender Distribution: Of the 65 patients enrolled, $70.77 \%(n=46)$ were males while $29.23 \%(n=19)$ were females. (Table 1, graph 1) Male to female ration was 2.4:1. Relatively, males spend more time outdoors exposing them to risk of trauma and subsequent ulcer, this could be one of the reasons for male preponderance.Another reason could be that our hospital receives patients from rural background who have a habit of walking barefoot, thus exposing themselves to injuries and contamination of wound.

\section{Age Distribution:}

Mean population age $=50.88 \pm 16.42$ years.

Patients age range $=21-80$ years.

Majority of the patients were found to be of 51 to 60 years.

Diabetic foot ulcers are common in elderly population. The reasons for the same may be that skin softens with age and can easily break even with trivial trauma. ${ }^{[20]}$ The ability of the cells to proliferate decreases as age progresses, response to stress and also immune response is diminished. Also the complications of diabetes that is neuropathy, vasculopathy worsen as the duration of uncontrolled diabetes increases.

3. Wagner Grading: Majority of the patients had Wagner grade III ulcer (44.62\%) followed by grade II ulcer in $24.62 \%$ of the patients. None of the patients enrolled in the present study had wagner grade I ulcer.

4. Risk Factors: When the risk factors presence was evaluated in the patients, $63.08 \%$ patient had suffered trauma, this was followed by peripheral neuropathy which was present in $60.00 \%$ patients. Among the patient enrolled, $36.92 \%$ were smokers. Considering the risk involved, $63.08 \%$ patient had suffered trauma, this was followed by peripheral neuropathy which was present in $60.00 \%$ patients. Among the patient enrolled, $36.92 \%$ were smokers. Neuropathy is a known precursor of trauma as it makes patient unaware of the trivial traumas that occur on daily basis and thus result in ulceration.

5. Duration of Diabetes: We classified the population on the basis of duration of diabetes diagnosis it was observed that $63.08 \%$ patients had diabetes for more than 10 years. It can be seen that as the duration of diseases increases so is the incidence of the ulceration, the reason for the same could be as follows, as the duration of disease increases so is the degree/severity of neuropathy and vasculopathy and thus predisposing the patients to ulceration that are resistant to heal. Patients are exposed to repeated traumas that cause ulcers to increase in size.

Table 2: Duration of diagnosis of diabetes

\begin{tabular}{|l|c|c|c|c|c|c|c|c|c|c|}
\hline \multirow{2}{*}{$\begin{array}{l}\text { Duration of diagnosis of } \\
\text { diabetes }\end{array}$} & \multicolumn{9}{|c|}{ Wagner grade } & \multicolumn{3}{c|}{ Total } \\
\cline { 2 - 13 } & \multicolumn{2}{|c|}{ II } & \multicolumn{2}{|c|}{ III } & \multicolumn{2}{|c|}{ IV } & \multicolumn{2}{|c|}{ V } & \multicolumn{2}{c|}{} \\
\cline { 2 - 13 } & N & $\mathbf{\%}$ & N & $\mathbf{\%}$ & N & $\%$ & N & $\%$ & N & $\%$ \\
\hline$\leq 5$ years & 2 & $3.08 \%$ & 6 & $9.23 \%$ & 3 & $4.62 \%$ & 0 & $0.00 \%$ & 11 & $16.92 \%$ \\
\hline$>5$ to $\leq 10$ years & 3 & $4.62 \%$ & 5 & $7.69 \%$ & 3 & $4.62 \%$ & 2 & $3.08 \%$ & 13 & $20.00 \%$ \\
\hline$\geq 10$ years & 11 & $16.92 \%$ & 18 & $27.69 \%$ & 9 & $13.85 \%$ & 3 & $4.62 \%$ & 41 & $63.08 \%$ \\
\hline Total & & & & & & & & & $\mathbf{6 5}$ & $\mathbf{1 0 0 \%}$ \\
\hline
\end{tabular}


6. USG Findings: USG showed presence peripheral vascular disease in $41.54 \%$ patients. vasculopathy predisposes to ischemic changes and ulcerations and reduce reduced host response to infections.

7. X-Ray Findings: X-ray showed presence of Charcot's joint, osteomyelitis, fracture and osteoporosis in $10.77 \%, 24.62 \%, 3.08 \%$ and $4.62 \%$ patients.

8. Incidence of Anaemia: Anemia was present in significant proportion of patients, $67.69 \%$, in the present study.
9. Management of Ulcer: Ulcer was managed conservatively in $38.46 \%$ of the patients. I \& D was performed in $35.38 \%$ of the patients. While amputation was performed in $12.31 \%$ of the patients.

10. Distribution of Bacterial Isolates: Staphylococcus aureus, Pseudomonas Aeruginosa, Klebsiella pneumonia, Streptococcus pyogenes and Proteus Mirabilis was present in $36.92 \%, 9.23 \%, 13.85 \%$, $18.46 \%$ and $10.77 \%$ patients, respectively.

Table 3: Distribution of the bacterial isolates

\begin{tabular}{|c|c|c|c|c|c|c|c|c|c|c|}
\hline \multirow{3}{*}{ Bacterial isolates } & \multicolumn{8}{|c|}{ Wagner grade } & \multirow{2}{*}{\multicolumn{2}{|c|}{ Total }} \\
\hline & \multicolumn{2}{|c|}{ II } & \multicolumn{2}{|c|}{ III } & \multicolumn{2}{|c|}{ IV } & \multicolumn{2}{|c|}{$\mathbf{V}$} & & \\
\hline & $\mathbf{N}$ & $\%$ & $\mathbf{N}$ & $\%$ & $\mathbf{N}$ & $\%$ & $\mathbf{N}$ & $\%$ & $\mathbf{N}$ & $\%$ \\
\hline Staphylococcus aureus & 9 & $13.85 \%$ & 12 & $18.46 \%$ & 2 & $3.08 \%$ & 1 & $1.54 \%$ & 24 & $36.92 \%$ \\
\hline Pseudomonas aeruginosa & 2 & $3.08 \%$ & 3 & $4.62 \%$ & 0 & $0.00 \%$ & 1 & $1.54 \%$ & 6 & $9.23 \%$ \\
\hline Klebsiella pneumonia & 2 & $3.08 \%$ & 3 & $4.62 \%$ & 3 & $4.62 \%$ & 1 & $1.54 \%$ & 9 & $13.85 \%$ \\
\hline Streptococcus pyogenes & 1 & $1.54 \%$ & 5 & $7.69 \%$ & 5 & $7.69 \%$ & 1 & $1.54 \%$ & 12 & $18.46 \%$ \\
\hline Proteus mirabilis & 1 & $1.54 \%$ & 0 & $0.00 \%$ & 5 & $7.69 \%$ & 1 & $1.54 \%$ & 7 & $10.77 \%$ \\
\hline None & 1 & $1.54 \%$ & 6 & $9.23 \%$ & 0 & $0.00 \%$ & 0 & $0.00 \%$ & 7 & $10.77 \%$ \\
\hline Total & 16 & $24.62 \%$ & 29 & $44.62 \%$ & 15 & $23.08 \%$ & 5 & $7.69 \%$ & 65 & $100 \%$ \\
\hline
\end{tabular}

11 Association of Amputation and Comorbid Conditions: It was observed that amputation was performed in all the patients with Wagner grade IV and $\mathrm{V}$ ulcers, while it occurred in $48.15 \%$ patients with vasculopathy and $33.33 \%$ patients with neuropathy. It was also observed that in those patients with proteus infection, amputation had to be performed in $100 \%$ patients.

Table 4: Association of amputation in patients with the various factors

\begin{tabular}{|c|c|c|c|}
\hline Factor & Total No. & No. undergoing Amputation & Percentage \\
\hline Neuropathy & 39 & 13 & $33.33 \%$ \\
\hline Vasculopathy & 27 & 13 & $48.15 \%$ \\
\hline \multicolumn{4}{|l|}{ WAGNER Grade } \\
\hline Grade II & 16 & 1 & $6.25 \%$ \\
\hline Grade III & 29 & 2 & $6.90 \%$ \\
\hline Grade IV & 15 & 15 & $100.00 \%$ \\
\hline Grade V & 5 & 5 & $100.00 \%$ \\
\hline \multicolumn{4}{|l|}{ Wound site infections with } \\
\hline Staphylococcus aureus & 24 & 3 & $12.50 \%$ \\
\hline Pseudomonas aeruginosa & 6 & 2 & $33.33 \%$ \\
\hline Klebsiella pneumonia & 9 & 4 & $44.44 \%$ \\
\hline Streptococcus pyogenes & 12 & 7 & $58.33 \%$ \\
\hline Proteus mirabilis & 7 & 7 & $100.00 \%$ \\
\hline
\end{tabular}


12. Resistance Pattern: Resistance pattern of the gram positive organisms was as shown in the table 12 . No resistance was observed to vancomycin and linezolid.

Table 5: Resistance pattern seen in organisms that are gram positive.

\begin{tabular}{|l|c|c|c|c|}
\hline \multirow{2}{*}{} & \multicolumn{2}{|c|}{ Staphylococcus Aureus (n=20) } & \multicolumn{2}{|c|}{ Streptococcus pyogenes (n=16) } \\
\cline { 2 - 5 } & $\mathbf{N}$ & $\mathbf{\%}$ & 4 & $25.00 \%$ \\
\hline Methicillin & 10 & $50.00 \%$ & 6 & $37.50 \%$ \\
\hline Gentamycin & 9 & $45.00 \%$ & 6 & $37.50 \%$ \\
\hline Amikacin & 17 & $85.00 \%$ & 7 & $43.75 \%$ \\
\hline Ceftriaxone & 13 & $65.00 \%$ & 6 & $37.50 \%$ \\
\hline Amoxy/clav & 17 & $85.00 \%$ & 15 & $93.75 \%$ \\
\hline Cotrimoxazole & 19 & $95.00 \%$ & 13 & $81.25 \%$ \\
\hline Ciprofloxacin & 14 & $70.00 \%$ & 8 & $50.00 \%$ \\
\hline Ampicillin & 19 & $95.00 \%$ & 15 & $93.75 \%$ \\
\hline Tetracycline & 19 & $95.00 \%$ & 1 & $6.25 \%$ \\
\hline Clindamycin & 4 & $20.00 \%$ & 5 & $31.25 \%$ \\
\hline Erythromycin & 8 & $40.00 \%$ & 0 & $0.00 \%$ \\
\hline Vancomycin & 0 & $0.00 \%$ & 0 & $0.00 \%$ \\
\hline Linezolid & 0 & $0.00 \%$ & & \\
\hline
\end{tabular}

Resistance pattern of the gram negative organisms was as shown in the table 13. No resistance was observed to Piperacillin+tazobactum, Imipenem and Meropenem.

Table 6: Resistance pattern of the gram negative organisms

\begin{tabular}{|c|c|c|c|c|c|c|}
\hline & \multicolumn{2}{|c|}{ Klebsiella pneumonia } & \multicolumn{2}{|c|}{ Pseudomonas } & \multicolumn{2}{|c|}{ Proteus } \\
\hline & $\mathbf{N}$ & $\%$ & $\mathbf{N}$ & $\%$ & $\mathbf{N}$ & $\%$ \\
\hline Gentamycin & 7 & $78 \%$ & 3 & $50 \%$ & 6 & $86 \%$ \\
\hline Amikacin & 5 & $56 \%$ & 3 & $50 \%$ & 2 & $29 \%$ \\
\hline Ciprofloxacin & 5 & $56 \%$ & 5 & $83 \%$ & 5 & $71 \%$ \\
\hline Ampicillin + Clavulanic acid & 7 & $78 \%$ & 2 & $33 \%$ & 2 & $29 \%$ \\
\hline Sulphomethoxazole/Trimethoprim & 3 & $33 \%$ & 3 & $50 \%$ & 1 & $14 \%$ \\
\hline Piperacillin+tazobactum & 0 & $0 \%$ & 0 & $0 \%$ & 0 & $0 \%$ \\
\hline Cefotaxime & 6 & $67 \%$ & 5 & $83 \%$ & 7 & $100 \%$ \\
\hline Ceftazidime & 4 & $44 \%$ & 5 & $83 \%$ & 4 & $57 \%$ \\
\hline Imipenem & 0 & $0 \%$ & 0 & $0 \%$ & 0 & $0 \%$ \\
\hline Meropenem & 0 & $0 \%$ & 0 & $0 \%$ & 0 & $0 \%$ \\
\hline
\end{tabular}

Ethics Committee Aprocal: Yes form Sviec

Source of Funding: Nil

\section{Conflict of Interest: Nil}

\section{Conclusion}

Diabetic foot ulcers pose a significant burden on the patients and on the health care system. The cost of disability, loss of work and lower extremity amputation extends beyond the economic impact, with regards to patient quality of life.

Proper management of diabetic infections requires appropriate antibiotic selection based on culture and antimicrobial susceptibility results; however, initial 
management comprises empirical antimicrobial therapy, which is often based on susceptibility data extrapolated from studies performed on general clinical isolates.

\section{References}

1. Levin ME. An overview of the Diabetic foot: Pathogenesis, Management and Prevention of Lesions. Int. J. Diab. Dev. Countries 1994; 14: 3941

2. Mondal S, et al. Clinico-microbiological profile and evaluation of antimicrobial sensitivity pattern of diabetic foot ulcers in India. Diabetic Foot Journal Middle East. Wounds Middle East 2019:6(1);3438 .

3. Kharroubi AT, Darwish HM (2015) Diabetes mellitus: The epidemic of the century. World $\mathrm{J}$ Diabetes 6(6): 850-867

4. World Health Organization (2016) Global Report on Diabetes. WHO, Geneva. Available at: https:// www.who.int/diabetes/global-report/en/(accessed 7 Aug 19).

5. John BB, Kenneth S, Polonsky K, Charles FB. Type 2 Diabetes Mellitus. In: Melmed S, Polonsky K, Larsen PR, Kronenberg H (2011) Williams Textbook of Endocrinology (12th edn). Elsevier/ Saunders, Philadelphia: pp1371-435.

6. WHO India. http://www.searo.who.int/india/ topics/diabetes_mellitus/en/. Assessed on 7 Aug 19.

7. International Diabetes Federation. IDF SEA members. Available from: https://idf.org/ournetwork/regions-members/south-east-asia/ members/94-india.html. Cited on: 7 Aug 19.

8. Viswanathan V, Thomas N, Tandon N. Profile of Diabetic Foot Complications and its Associated Complications. JAPI 2005; 53: 933-36.

9. Papatheodorou K, Banach M et al. Complications of diabetes 2016. J Diabetes Res 2016:6989453
10. Edmonds Diabetic Foot Ulcer: Practical treatment recommendations. Drugs 66(7): 914-29

11. Richard JL and Schuldiner S. Epidemiology of diabetic foot problems. (2008). Rev Med Interne:29(2);222-230.

12. Rauwerda JA. Foot debridement: anatomic knowledge is mandatory. Diabetes Metab Res Rev 2000;16(1):S23-6.

13. Wagner FW. The diabetic foot. Orthopaedics. 1987;10:163-72.

14. Boulton AJ The diabetic foot: a global view. Diabetes Metab Res Rev 16: S2-5.

15. Jain SK, et al. Bacteriological Profile of Diabetic Foot Ulcer Special Reference to Drug-resistant Strains in a Tertiary Care Center in North-East India. 2017;21:688-94.

16. Huang Y, Cao Y, Zou M, Luo, et al. Comparison of tissue versus swab culturing. Int $\mathrm{J}$ Endocrinol 2016;2016:8198714.

17. Singh N, Armstrong DG, Lipsky BA. Prevention of foot ulcers in patients with diabetes. JAMA 2005;293:217-28.

18. Andersen CA. The diabetic foot. Surg Clin North Am. 2007;87:1149-77, $x$.

19. Falanga V (1998) The wound healing and chronic wounds. J Cutaneous Med Surg 3: S1.

20. Anand A, et al. A clinico-microbiological study of diabetic foot ulcer in tertiary care hospital in India. Int Surg J. 2016 May;3(2):669-673.

21. Mohanty DP, et al.Clinico-Microbiological Profile of Diabetic Foot Ulcer: The common Anatomical site. JMSCR.2017:5(8);26585-93.

22. Hartemann-Heurtier A, Jacqueminet S et al. Diabetic foot ulcer and multidrug-resistant organisms: risk factors and impact. 2004:Diabet Med 21(7): 710-5. 